Sains Malaysiana 48(8)(2019): 1745-1752

http://dx.doi.org/10.17576/jsm-2019-4808-21

\title{
Novel Surface-Enhanced Raman Scattering Substrate based on Functionalized Silicon Nanowires
}

(Raman Permukaan-Dipertingkatkan Sebaran Substrat Baru berasaskan Silikon Berfungsi Wayar Nano)

\author{
IRAM MAHMOOD*, ISHAQ AHMAD \& ISHFAQ AHMAD
}

\begin{abstract}
This study reports synthesis of a new Surface-Enhanced Raman Scattering (SERS) substrate using Silicon nanowires (SiNW's) arrays, produced through chemical etching, and functionalized by tailoring their surface chemistry with nitrogen containing groups. From SEM characterization, phenomenon of micro channel formation, porosity and amorphous nature for the as prepared SiNWs was observed. Photoluminescence (PL) spectrum showed that these nanowires have broad emission band in the range of 500-900 $\mathrm{nm}$. Also, change in the surface chemistry of Si nanowires after nitrogen treatment was observed by elemental analysis, EDX and X-ray photoelectron spectroscopy. The data showed that raising the modification temperature also increased the nitrogen content. At high temperature, pyridine and aromatic amines were the dominant functional groups while a small amount of quaternary nitrogen and protonated amide were also present. Methylene blue (MB) was used as a probe molecule to investigate SERS activities of functionalized SiNWs. The enhancement factor was estimated to be $10^{7}-10^{9}$. Interaction of nitrogen containing groups on the surface of SiNWs with $M B$ molecules resulted in high adsorption of MB on the substrate and higher signal detection by SERS.
\end{abstract}

Keywords: Methylene blue; photoluminescence; Raman scattering; surface enhanced Raman scattering; silicon nanowires

ABSTRAK

Kajian ini melaporkan sintesis substrak Raman Permukaan-Dipertingkatkan Sebaran (SERS) menggunakan susunan nanowayar silikon melalui proses punaran secara kimia, serta penukaran sifat kimia permukaan dengan kumpulan berfungsi bernitrogen. Melalui pencirian SEM, pembentukan saluran mikro, liang dan ciri-ciri amorfous telah diperhatikan. Spektrum fotoluminesens menunjukkan bahawa nanowayar yang terhasil mempunyai jalur pancaran lebar dalam julat 500-900 nm. Di samping itu, perubahan kimia permukaan nanowayar selepas rawatan nitrogen telah dikaji dengan analisis unsur, EDX dan spektroskopi fotoelektron sinar-X. Data yang diperoleh menunjukkan bahawa ubahsuaian melalui suhu juga meningkatkan kandungan nitrogen. Pada suhu tinggi, piridina dan amina aromatik adalah kumpulan berfungsi utama dengan terdapat kandungan kecil nitrogen kuaternari dan amida juga terbentuk. Metilena biru(MB) telah digunakan sebagai molekul model untuk mengkaji aktiviti SERS bagi substrak SiNWs yang terhasil. Faktor peningkatan sebanyak $10^{7}-10^{9}$ telah diperoleh. Interaksi antara kumpulan berfungsi nitrogen pada permukaan SiNWs dan molekul MB menyebabkan penjerapan MB yang tinggi, lalu mencapai pengesanan isyarat SERS yang tinggi.

Kata kunci: Fotoluminesens; metilena biru; serakan Raman; serakan Raman permukaan-dipertingkatkan; silikon nanowayar

\section{INTRODUCTION}

Surface-Enhanced Raman Spectroscopy (SERS) has received enormous interest since 1977 because of its ability to produce 3-14 orders enhancement in Raman signal (Kneipp et al. 1997; Nie et al. 1997; Tian et al. 2006). It has been recognized as a promising spectroscopic probe for ultra-sensitive detection of biological and chemical analytes (Pavan et al. 2007). Due to advancements in SERS technology, scientists are able to detect a single molecule (Cotton et al. 1991). In general, unique vibrational signals for individual analytes provide an insight to their chemical and structural information. Raman bands are $\sim 100$ times narrower, compared to fluorescence peaks, which reduce spectral overlap and make multiple labels feasible. The chemical/physical properties of the substrate and probing molecule are crucial to obtain optimum excitation wavelength for Raman scattering and multilabel readout by single excitation wavelength. It is possible to have less photo bleaching with Raman signals, which enables lower detection limits and better repeatability (Zhang et al. 2010). Despite the fact that SERS has gained good reputation as an information-rich spectroscopy for detection of many classes of analytes, in some isolated instances down to the single molecule detection limit, its future development critically depends upon the techniques for nanofabrication. To this aim, developing synthetic approaches for making SERS substrates with well-defined structures is greatly desired.

Silicon is one of the most enthralling candidates for plasmon-free surface enhanced Raman scattering (SERS), 
due of its high-refractive index and thermal stability. Moreover, non-plasmonic silicon-based SERS substrates are chemically inert, thermally stable, and relatively simple to fabricate.

Guided by this anticipation, we report here the use of an unconventional nanofabrication approach to produce efficient SiNWs based SERS substrate. We have investigated and demonstrated the preparation of SiNWs arrays and patterns using chemical etching of crystalline silicon substrate. Surface of Si nanowires was modified by functionalizing them with various $\mathrm{NH}$-groups using $\mathrm{NH}_{3}$ gas under high pressure and at various temperatures for the preparation of highly-sensitive surface-enhanced Raman spectroscopy (SERS) substrates. Adsorption of dyes to various surfaces has been known since many years. The SERS activities of these substrates were investigated using methylene blue as probe molecule. Comparison between the normal Raman spectra (NRS) and SERS spectra of adsorbed MB is also studied. Functionalized SiNWs can provide strong enhancement in Raman scattering and high-sensitivity detection of MB. This approach has some advantages as it is simple, inexpensive and easier to incorporate functional groups as well as micro channels in the SiNWs arrays.

\section{EXPERIMENTAL DETAILS}

\section{FABRICATION AND CHARACTERIZATION} OF SERS SUBSTRATE

SiNWs arrays were prepared by Ag-assisted chemical etching of n-Si (100) wafer as reported by Zhang et al. (2008). The commercial Si wafers were cut up to $2 \times 2 \mathrm{~cm}^{2}$ and washed with water and acetone and then immersed in oxidant solution containing $\mathrm{H}_{2} \mathrm{SO}_{4}(97 \%)$ and $\mathrm{H}_{2} \mathrm{O}_{2}(35 \%)$ with a volume ratio $3: 1$ for 10 min under room temperature to remove organics and to form a thin oxide layer. After that, they were etched with $5 \%$ HF aqueous solution for 3 min under room temperature and the obtained samples were H-terminated. The Si wafers were immediately placed into an Ag coating solution containing 4.8 M HF and 0.005 $\mathrm{M} \mathrm{AgNO}_{3}$, and stirred slowly for 1 min under ambient atmosphere. Once a uniform layer of Ag nanoparticles (AgNPs) coating has been formed, wafers were washed with water to remove the extra $\mathrm{Ag}^{+}$ions and then immersed in etchant composed of $4.8 \mathrm{M} \mathrm{HF}$ and $\mathrm{H}_{2} \mathrm{O}_{2}$. After $30 \mathrm{~min}$ etching in the dark place under room temperature, wafers were washed repeatedly with water and then immersed in dilute $\mathrm{HNO}_{3}(1: 1 \mathrm{v} / \mathrm{v})$ to dissolve the $\mathrm{Ag}$ catalyst. The wafer surfaces became deep black in color, and their back sides in gray. Further, these wafers were washed with 5\% $\mathrm{HF}$ again to remove the oxide layer and cleaned with water and then dried under $\mathrm{N}_{2}$ flow. For functionalization with nitrogen containing groups, SiNWs arrays were kept in a hot furnace (limber/Blue), operated at high temperatures $\left(600-800^{\circ} \mathrm{C}\right)$ and ammonia gas was introduced under high pressure (100 mbar) for $1 \mathrm{~h}$.
Their performance was determined both by their texture and surface chemistry. Surface morphology and elemental analysis of Functionalized SiNW's was performed by various techniques. SEM images and EDX spectrum of the SiNWs were obtained with Philips XL30 ESEMFEG while their Surface functionalization and elemental analysis was performed on Scanning Auger and XPS (PHI Model 5802) instrument. Photoluminescence measurements were performed in a scanning confocal Raman spectrometer (RENISHAW with a $633 \mathrm{~nm} \mathrm{He-Ne}$ laser).

\section{RAMAN SCATTERING MEASUREMENTS}

Analytical grade Methylene Blue (MB), purchased from ACROS, was used without further purification. All solutions were prepared in distilled water as solvent. The SERS substrate (Functionalized SiNWs array) was cut up to 3 ' $3 \mathrm{~mm}^{2}$ squares. $1.0 \mathrm{~mL}$ of the solution was placed on the Raman substrate, and dried under $\mathrm{N}_{2}$ gas flow at room temperature. A RENISHAW Raman Microscope with WIRE2 software and $632.8 \mathrm{~nm}$ emission line of a He-Ne laser was used for measurement. With a $50 \mathrm{X}$ objective, the laser point on the sample surface was focused to about $2 \mathrm{~mm}$ with a power of about $20 \mathrm{~mW}$. The integration time for one spectrum was $10 \mathrm{~s}$, and single scan was performed. To ensure of the repeatability and reliability of the measured results, on each sample we took multiple measurements at different locations and averaged the spectra. All Raman spectra were collected under the same conditions. The intensity of the measured Raman spectra was reproducible within $60 \%$ when collected at different spots around the central area of the sample.

\section{RESULTS AND DISCUSSION}

\section{CHARACTERIZATION}

The top-view SEM images of SiNW's are shown in Figure 1(a). It is clear that as-prepared SiNWs are uniform over a large area.

During functionalization, while employing $\mathrm{NH}_{3}$ gas, some Si was consumed in the formation of nitrogen containing groups on the surfaces of SiNWs. This sacrificial reaction obviously changed the surface morphology and alignment of SiNW's arrays. SEM investigations further confirmed that after high temperature and $\mathrm{NH}_{3}$ gas treatment SiNWs became more porous and amorphous. In addition, large numbers of micro channels have been introduced at high temperature, as shown in Figure 1(b).

Due to concentration gradient of $\mathrm{NH}_{3}$, more nitrogen containing groups would prefer to functionalize SiNWs near the surface. Hence, SiNWs became more amorphous and some pores can be observed on their surface, as shown in Figure 2(a)-2(e). Figure 2(f) is representative EDX analysis result for nitrogen containing groups with functionalized SiNWs, which confirmed the presence of nitrogen in the sample. 


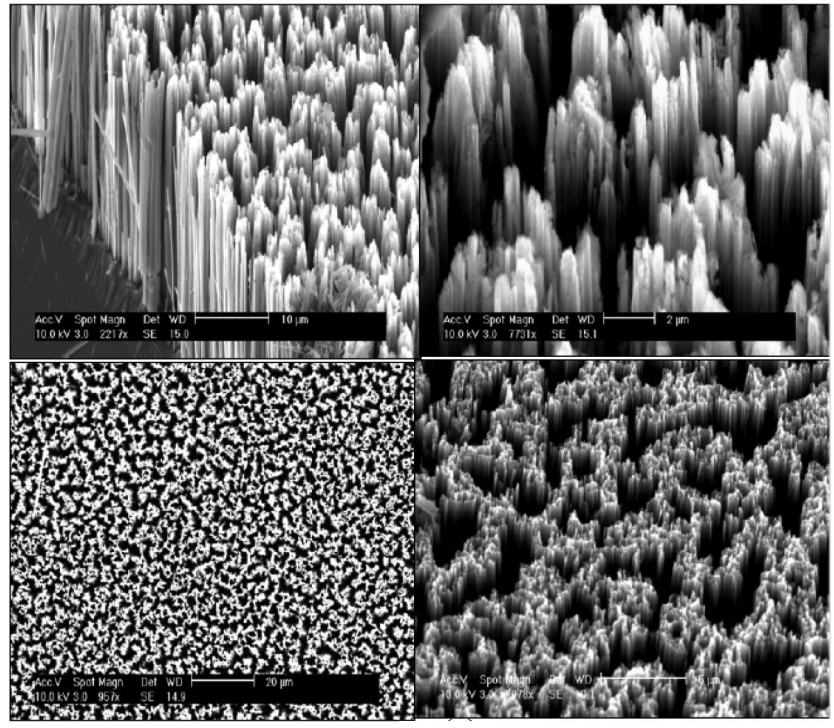

(a)

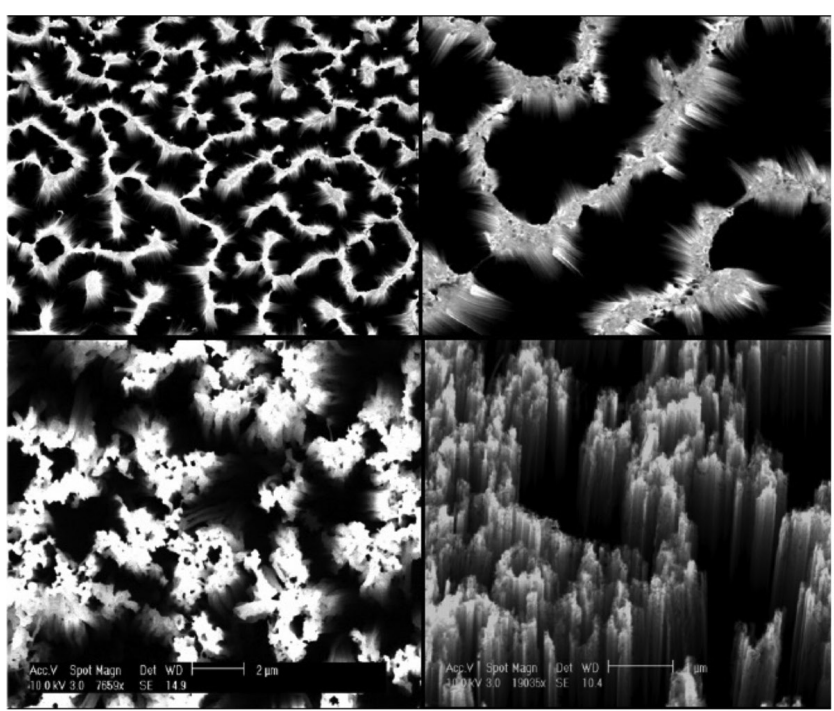

(b)

FIGURE 1. a) Top view SEM images of SiNWs arrays b) Formation of Micro-channels within SiNWs after treatment with $\mathrm{NH}_{3}$ under high pressure and temperature

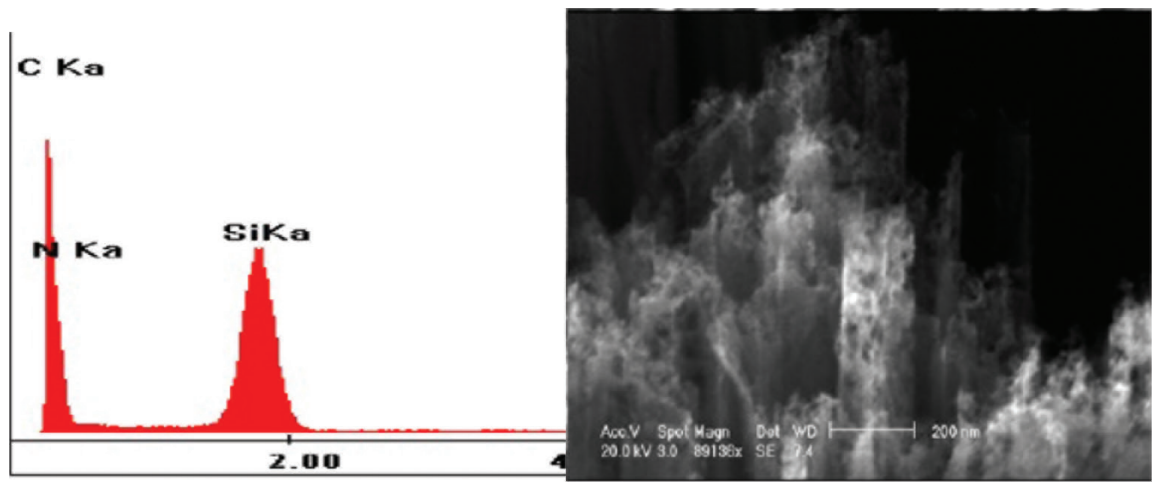

FIGURE 2. The representative SEM images of functionalized SiNWs, a-e) a-porous and amorphous surfaces of SiNWs cab be observed f) and their corresponding EDX analysis 
On the whole, substrate exhibits micro-channeled SiNWs arrays, though some pores and amorphous structure appeared in certain areas of SiNWs, owing to their functionalization. These investigations showed that the SiNWs were directly functionalized by employing $\mathrm{NH}_{3}$ and high temperature with no barrier, which may contribute to SERS activity.

Interestingly, after modification the surface chemistry of SiNW's obviously changed by the formation of nitrogen containing functional groups on the surface which was confirmed by elemental analysis and X-ray photoelectron spectroscopy. Total elemental analysis results of virgin and modified SiNW's are shown in Table 1.

The data showed that reactions between ammonia and the silicon surface increased the nitrogen content which further enhanced by rising the modification temperature. The same trends were observed from XPS analysis results. The curve fitting of the N1s spectra of the modified SiNW's indicated that different types of nitrogen functional groups were formed on the SiNW's surface as presented in Figure 3 and Table 2.

Pyridine and aromatic amines were the dominant functional groups and a small amount of them converted to quaternary nitrogen when tailoring temperature was increased (Chun \& Xijun 2011). These basic nitrogen functional groups, in addition to porous and microchannel formation in SiNWs, had a significant effect on SERS detection of Methylene blue. The SERS detection was enhanced with the amount of nitrogen groups incorporated due to an acid-base interaction between MB and substrate. However, the surface morphology changed more significantly from $500^{\circ} \mathrm{C}$ to $600^{\circ} \mathrm{C}$ than from $700^{\circ} \mathrm{C}$ to $800^{\circ} \mathrm{C}$. Although the similar increase in surface nitrogen concentration was observed. This might be explained by the stereo effect mechanism. Since SiNWs, modified at $800^{\circ} \mathrm{C}$, had relatively much larger porous area than those modified at lower temperatures, the dye molecules could have more opportunities to fully contact with the functional groups attached to the surface. Therefore, the SERS signals of the sample modified at $800^{\circ} \mathrm{C}$ was greatly enhanced. While in the case of the samples modified at lower temperatures, the nitrogen functional groups formed on the SiNWs surface may not be totally utilized during the dye adsorption process due to smaller number of pores and micro channel formation (Figure 3).

Hence, the sample modified at $800^{\circ} \mathrm{C}$ was the most effective as it showed the highest number of nitrogen containing groups being incorporated to the SiNWs. These novel functionalized SiNWs are promising substrates for SERS, as it can be applied to most reactive and acidic dye detection.

\section{OPTICAL PROPERTIES OF FUNCTIONALIZED SINWS}

Raman spectroscopy is very sensitive to the lattice structure and the crystal symmetry. Raman studies of SiNWs have been reported in literature, in detail (Li et al. 1999). Raman spectroscopy (peak energy, peak width, and symmetry) of nano-Si changes with the reduction of the size. The Raman spectrum of Si nanowires is symmetric, centered at 521 $\mathrm{cm}^{-1}$ in our experiments, which is normally reported for amorphous or porous Silicon structures (Figure 4(a)).

To investigate the luminescence properties of the assynthesized Si nanowires, we performed PL measurement. Figure 4(b) presents the PL spectrum of the Si nanowires, indicating a broad emission band in the range of 500$900 \mathrm{~nm}$. The PL spectrum also shows bands at 605-640 and 680-690 $\mathrm{nm}$, respectively, which are consistent with the PL of porous silicon (inset of Figure 4(b)). The broad band consists of a broad emission peak centered

TABLE 1. Elemental analysis of virgin and modified SiNWs using XPS

\begin{tabular}{|c|c|c|c|c|}
\hline Sample & $\mathrm{C} 1 \mathrm{~s}$ & N1s & O1s & $\operatorname{Si} 2 p$ \\
\hline SiNWs & 2.61 & 0.00 & 53.84 & 43.55 \\
\hline SiNWs- $\mathrm{NH}_{3}-500^{\circ} \mathrm{C}, 60 \mathrm{~min}$ & 4.64 & 0.57 & 62.63 & 32.17 \\
\hline SiNWs- $\mathrm{NH}_{3}-600^{\circ} \mathrm{C}, 60 \mathrm{~min}$ & 4.67 & 1.01 & 62.00 & 32.32 \\
\hline $\mathrm{SiNWs}-\mathrm{NH}_{3}-700^{\circ} \mathrm{C}, 60 \mathrm{~min}$ & 10.68 & 0.53 & 53.32 & 35.47 \\
\hline $\mathrm{SiNWs}-\mathrm{NH}_{3}-800^{\circ} \mathrm{C}, 60 \mathrm{~min}$ & 3.35 & 1.61 & 60.23 & 34.81 \\
\hline
\end{tabular}

TABLE 2. XPS analysis of nitrogen functional groups on virgin and modified SiNW's

\begin{tabular}{lcccc}
\hline Sample & $\begin{array}{c}\text { pyridine-like } \\
\text { nitrogen } \\
(398-399 \mathrm{eV})\end{array}$ & $\begin{array}{c}\text { Aromatic } \\
\text { amines } \\
(400-00.5 \mathrm{eV})\end{array}$ & $\begin{array}{c}\text { Quaternary } \\
\text { nitrogen } \\
(401-402 \mathrm{eV})\end{array}$ & $\begin{array}{c}\text { Protonated } \\
\text { amide } \\
(403-403.2 \mathrm{eV})\end{array}$ \\
\hline SiNWs & - & - & - & - \\
SiNWs-NH $-500^{\circ} \mathrm{C}, 60 \mathrm{~min}$ & 100 & - & - & - \\
$\mathrm{SiNWs}-\mathrm{NH}_{3}-600^{\circ} \mathrm{C}, 60 \mathrm{~min}$ & 87.5 & 12.5 & - & - \\
$\mathrm{SiNWs}-\mathrm{NH}_{3}-700^{\circ} \mathrm{C}, 60 \mathrm{~min}$ & 81.4 & 18.6 & - & - \\
$\mathrm{SiNWs}-\mathrm{NH}_{3}-800^{\circ} \mathrm{C}, 60 \mathrm{~min}$ & 80.2 & 10.8 & 10 & - \\
\hline
\end{tabular}




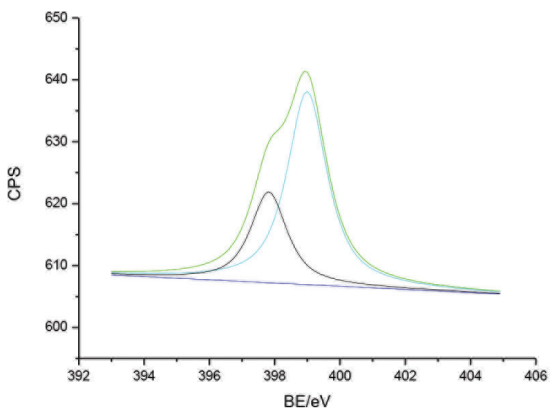

(a)

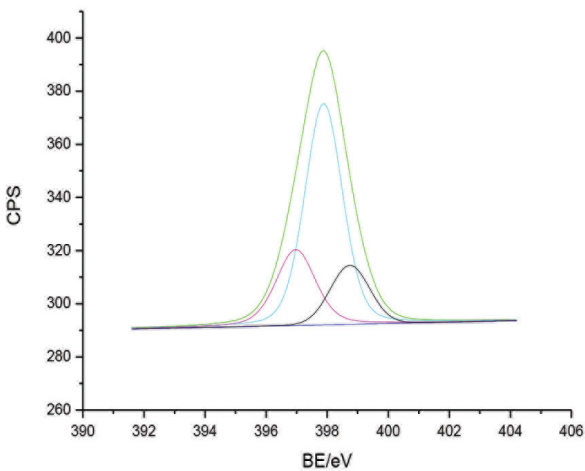

(c)

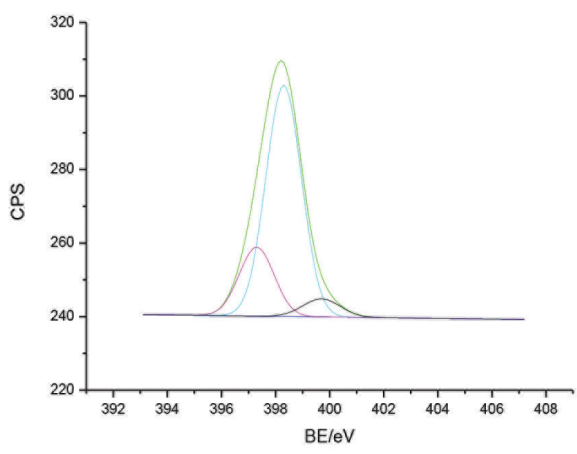

(b)

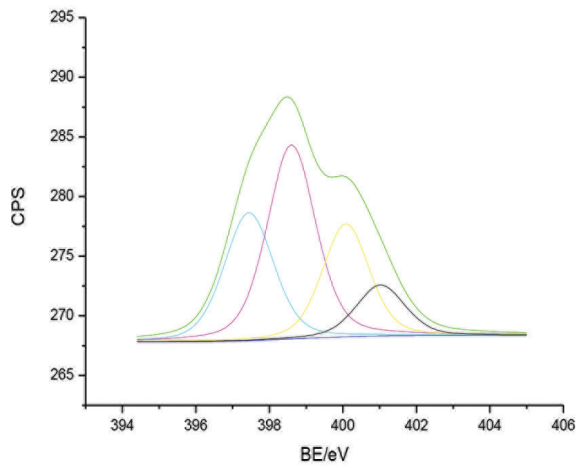

(d)

FIGURE 3. Representative N1s XPS spectrum for modified SiNWs a) SiNWs- $\mathrm{NH}_{3}-500^{\circ} \mathrm{C}, 60 \mathrm{~min}$, b) $\mathrm{SiNWs}-\mathrm{NH}_{3}-$ $\left.600^{\circ} \mathrm{C}, 60 \mathrm{~min}, \mathrm{c}\right) \mathrm{SiNWs}-\mathrm{NH}_{3}-700^{\circ} \mathrm{C}, 60 \mathrm{~min}$, and d) $\mathrm{SiNWs}-\mathrm{NH}_{3}-800^{\circ} \mathrm{C}, 60 \mathrm{~min}$

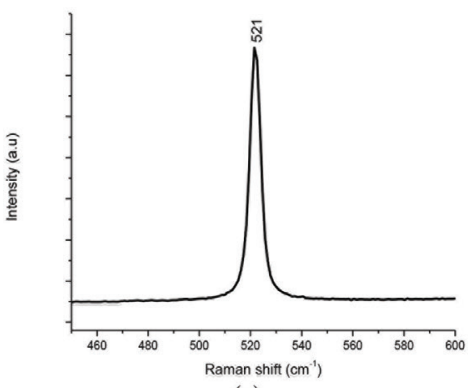

(a)

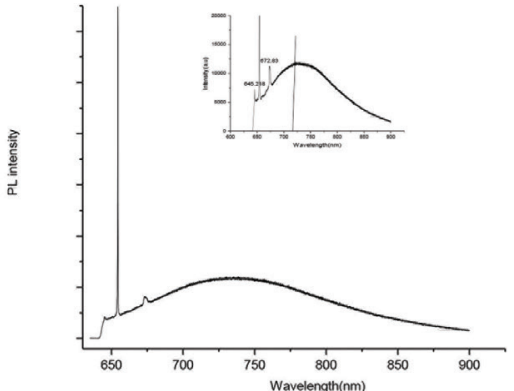

(b)

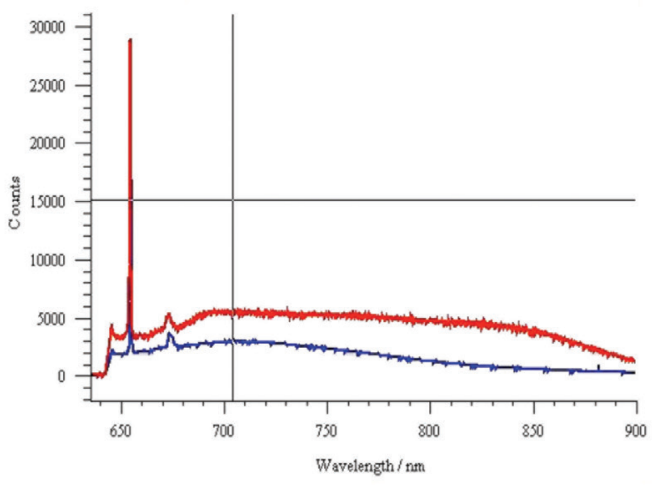

(c)

FIGURE 4. a) Raman spectra of the functionalized SiNWs b) PL spectra of the functionalized SiNWs at room temperature and c) Representative Raman (blue line) and PL spectra (red line) of functionalized SiNWs. The power output of laser at samples was about $70 \mathrm{~W} / \mathrm{cm}^{2}$ 
at about $\sim 700-750 \mathrm{~nm}$ and $\sim 800 \mathrm{~nm}$. This phenomenon can be attributed to the functionalization of the surface of Si nanowire. Actually, the functionalization with nitrogen containing groups played an important role for the luminescence of the Si nanowires. During the growth process, the surface of the Si nanowire initially consists of $\mathrm{Si}-\mathrm{O}$ and $\mathrm{Si}$ dangling bonds. Then the large stress leads to the distortions in the Si lattice and the partial break of the $\mathrm{Si}-\mathrm{O}-\mathrm{Si}$ bonds at the interface between the Si nanowire and the nitrogen containing groups. Due to the oxygen atoms interconnecting the crystalline $\mathrm{Si}$ core with the nitrogen containing functional groups, a novel electronic state in the interfacial region can be created. Therefore, the band at about $750 \mathrm{~nm}(1.65 \mathrm{eV})$ PL peak can be assigned to the surface radiative recombination centers located at this interface region. Hence, we can confirm that the $750 \mathrm{~nm}$ PL peak results from SiNWs.

Some experimental investigations on the $\mathrm{Si} / \mathrm{SiO} x$ films such as porous silicon (Torchynska et al. 2003) and oxidized Si nanometer-sized spheres (Qianwang et al. 1996) have also shown that in these systems the $\mathrm{Si} / \mathrm{SiO} x$ interfacial region is responsible for the $1.65-1.7 \mathrm{eV}$ PL peak. These results are in good agreement with our current PL peak position (Figure 4(c)).

\section{SERS ANALYSIS}

Raman spectra were collected for SERS substrates coated with $1.0 \mathrm{~mL}$ of different concentrations of Methylene Blue (MB) aqueous solutions. Figure 5 shows a collection of Raman spectra that illustrates the efficiency of the SERS substrate. All the peaks can be assigned to the characteristic Raman spectral features of MB, which confirmed that MB adsorbed on functionalized SiNWs substrates. The characteristic peaks of MB at around 1618 and $445 \mathrm{~cm}^{-1}$, which have been assigned to $\mathrm{C}-\mathrm{C}$ stretching and $\mathrm{C}-\mathrm{N}-\mathrm{C}$ skeletal bending were obvious in the SERS spectra, indicate that the molecules were adsorbed on the substrates well (Naujok et al. 1993). The Raman shifts, relative intensity and assignments of the main vibrational modes observed in the SERS and NRS spectra are listed in Table 3. The reported results are also presented for comparison (Hulchineon et al. 1984; Ruan et al. 2007) (Figure 5).

Compared with the Normal Raman Spectra, it is noticeable that several additional Raman bands show up in the SERS spectra, such as 1032, 1004, 890, 615. The shifts and splits of a few Raman bands indicate that methylene blue molecules may be chemisorbed on the functionalized SiNWs, so chemical effects can be the main mechanism responsible for the relative shifts.

Figure 5(a) clearly shows that the substrate SiNW's functionalized under $\mathrm{NH}_{3}$ gas treatment at $800^{\circ} \mathrm{C}$ for 1 h (sample A), exhibited the highest SERS enhancement and on average the SERS signal intensity was at least three times stronger than that of sample $\mathrm{C}$ under $\mathrm{NH}_{3}$ gas treatment at $600^{\circ} \mathrm{C}$ for $1 \mathrm{~h}$. As temperature increased to $800^{\circ} \mathrm{C}$, larger amount of nitrogen containing groups

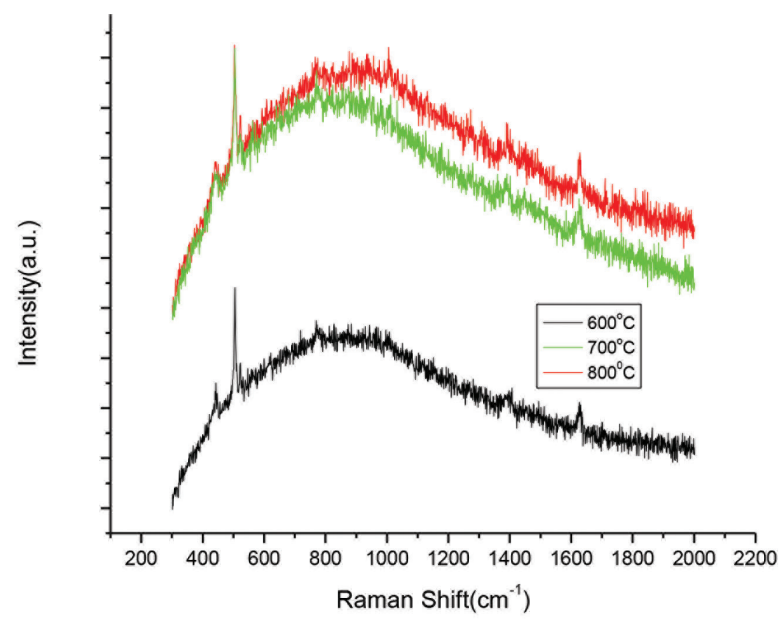

(a)

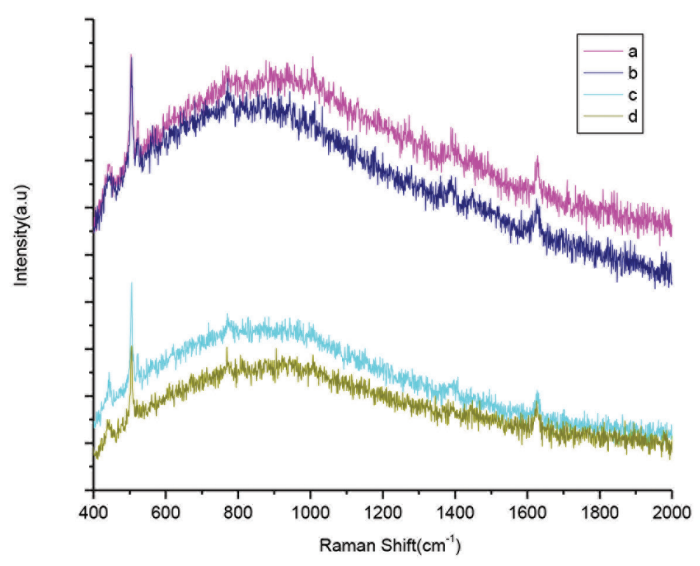

(b)

FIGURE 5. (a) Raman spectra of $10^{-7} \mathrm{M}$ MB on SiNW substrates obtained at different treatment temperatures under $\mathrm{NH}_{3}$ : and (b) Raman spectra of MB of different concentrations on $\mathrm{SiNW}$ sample A: curve a $10^{-7} \mathrm{M}$, b $10^{-8} \mathrm{M}, \mathrm{c} 10^{-9} \mathrm{M}$, and d $10^{-10} \mathrm{M}$

were incorporated into the SiNWs. Significantly, the SERS signals on sample A showed less than $30 \%$ fluctuation over the entire wafer, indicating overall good uniformity and reliability of the substrate. MB solutions of different concentrations $\left(10^{-6} \mathrm{M}\right.$ to $\left.10^{-8} \mathrm{M}\right)$ were used to study the SERS dynamical range. Figure 5(b) shows that MB amount, as low as $10^{-8} \mathrm{M}$ can be detected on the modified SiNWs substrate.

In order to check the reproducibility of the SERS signals obtained with functionalized SiNWs substrates, we took measurements from different regions, and almost identical intensity and position of the bands were obtained.

Based on previous studies (Green et al. 2003; Laurent et al. 2005), the apparent SERS enhancement factor (EF) can be determined from experiments. The SERS enhancement factor can be written as

$$
\frac{I_{\text {SERS }}}{I_{\text {Raman }}} \frac{N_{\text {Raman }}}{N_{\text {SERS }}}
$$


where $I_{\text {SERS }}$ and $I_{\text {Raman }}$ are the intensity of the same Raman band under SERS and normal Raman condition, respectively. $N_{\text {Raman }}$ and $N_{\text {SERS }}$ are the number of analytes molecules illuminated by the laser focus spot under normal Raman and SERS condition, respectively. Table 3 provides details about Raman shifts, relative intensity and peak assignments of methylene blue.

During experiments, the Raman measurement settings including the laser power were kept constant. The strongest Raman peak at $1618 \mathrm{~cm}^{-1}$ was selected for determining the SERS enhancement factor (Figure 6). The normal Raman spectra were collected from Sudan dyes put on SiNWs arrays without any functionalization. This estimation is based on the assumption that molecules were uniformly dispersed in the region which was made wet with the solution. By doing so, the EF of the substrate was estimated to be $10^{7}-10^{9}$ which is comparable to other SERS substrates reported for MB detection (Baia et al. 2006; Xiao et al. 2007).

Chemical effect involves an enhanced scattering process associated with chemical interaction between the dye molecule and the SERS surface. Furthermore, since functionalized SiNWs are completely free of organic contaminations, which are usually attendant on metal substrates. The clean surface of functionalized SiNWs would expose more active centers for interactions with analytical molecules, thus additionally increasing the chemical enhancement effect.

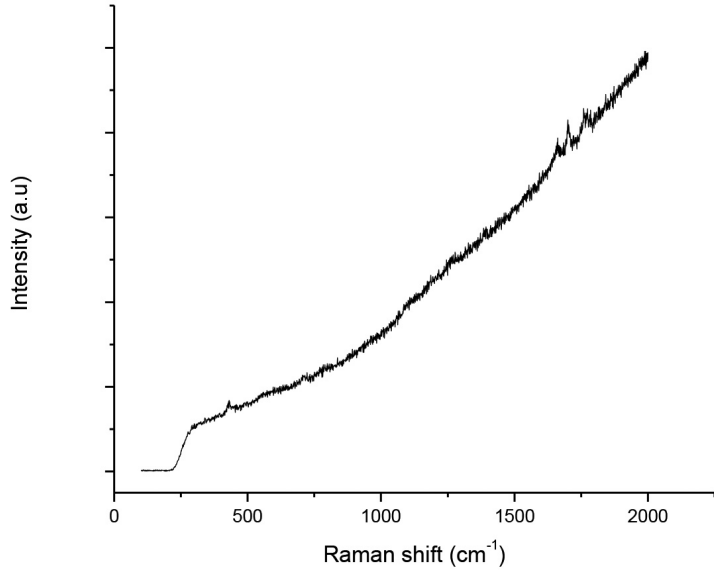

FIGURE 6. SERS spectrum of MB on SiNW array substrate without modification

\section{CONCLUSION}

In conclusion, a unique high-efficiency SERS substrate based on SiNW's array attached to a Si wafer and functionalized with nitrogen containing groups is presented. The substrate is easily fabricated and free from organic contaminations, which is favorable for higher sensitivity and lower detection limit. The Raman spectra of Methylene Blue (MB) was investigated in details, showing that molecular structure-specific Raman bands can be distinctly detected from a few molecules of MB

TABLE 3. The Raman shifts, relative intensity and peak assignments of methylene blue

\begin{tabular}{|c|c|c|c|c|c|c|}
\hline $\begin{array}{l}\text { Solid MB } \\
\text { powders }\end{array}$ & $\begin{array}{c}\text { On } \\
\text { SiNWs-NH }- \\
500^{\circ} \mathrm{C}, 60 \mathrm{~min}\end{array}$ & $\begin{array}{c}\text { On } \\
\text { SiNWs-NH }- \\
-600^{\circ} \mathrm{C}, 60 \mathrm{~min}\end{array}$ & $\begin{array}{c}\text { On } \\
\mathrm{SiNWs}^{-\mathrm{NH}_{3}-} \\
700^{\circ} \mathrm{C}, 60 \mathrm{~min}\end{array}$ & $\begin{array}{c}\text { On } \\
\text { SiNWs-NH }- \\
800^{\circ} \mathrm{C}, 60 \mathrm{~min}\end{array}$ & $\begin{array}{l}\text { Reported } \\
\text { results Band } \\
\text { assignments }\end{array}$ & $\begin{array}{c}\text { Band } \\
\text { assignments }\end{array}$ \\
\hline $1618(s)$ & 1626 & 1621 & 1614 & 1617 & $\begin{array}{l}1617(s) \\
1597(w)\end{array}$ & $\begin{array}{l}v(C-C) \text { ring } \\
v(C-C) \text { ring }\end{array}$ \\
\hline $1544(w)$ & 1552 & 1543 & 1547 & $\begin{array}{l}1537 \\
1541\end{array}$ & $1513(w)$ & $v_{\text {asym }}(C C)$ \\
\hline $1441(w)$ & 1443 & $\begin{array}{l}1437 \\
1430\end{array}$ & 1448 & 1446 & $1442(\mathrm{~m})$ & $v_{a s y m}(C N)$ \\
\hline $1396(\mathrm{~m})$ & 1407 & $\begin{array}{l}1392 \\
1389\end{array}$ & 1391 & 1394 & $1396(\mathrm{~m})$ & $\alpha(C H)$ \\
\hline $1331(w)$ & & 1308 & 1334 & 1342 & & \\
\hline $1272(w)$ & 1281 & 1273 & 1281 & 1284 & $1301(\mathrm{~m})$ & \\
\hline $1181(\mathrm{~m})$ & 1192 & 1189 & 1178 & 1185 & $\begin{array}{c}1184(\mathrm{~m}) \\
1121\end{array}$ & $\begin{array}{c}v(C N) \\
\gamma(C H)\end{array}$ \\
\hline $1067(w)$ & 1051 & 1063 & $\begin{array}{l}1062 \\
1070\end{array}$ & $\begin{array}{l}1066 \\
1004\end{array}$ & $1030(\mathrm{~m})$ & $\beta(C H)$ \\
\hline $768(w)$ & 770 & $\begin{array}{l}766 \\
756\end{array}$ & 771 & $\begin{array}{l}770 \\
890\end{array}$ & & \\
\hline $677(w)$ & 671 & 664 & 680 & 677 & $\begin{array}{l}670(w) \\
612(m)\end{array}$ & $\begin{array}{c}\gamma(C H) \\
\delta(\mathrm{C}-\mathrm{S}-\mathrm{C})\end{array}$ \\
\hline $497(w)$ & 481 & 486 & 491 & 493 & $502(\mathrm{~m})$ & $\delta(\mathrm{C}-\mathrm{N}-\mathrm{C})$ \\
\hline
\end{tabular}


to hundreds of molecules on the new SERS substrate. The SERS enhancement factor was estimated to be as large as $10^{7}-10^{9}$. The easy tenability of surface plasmon resonance and enormous Raman enhancement effect of these Silicon nanostructures recommend them as promising candidates for biological and medical research.

\section{ACKNOWLEDGEMENTS}

Authors are thankful to the deanship of scientific research at King Khalid University, Kingdom of Saudi Arabia for their technical and administrative support.

\section{REFERENCES}

Baia, L., Baia, M. \& Popp, A.J. 2006. Gold films deposited over regular arrays of polystyrene nanospheres as highly effective SERS substrates from visible to NIR. J. Phys. Chem. B. 110(47): 23982-23986.

Chun, H.E. \& Xijun, H.U. 2011. Anionic dye adsorption on chemically modified ordered mesoporous carbons. Ind. Eng. Chem.Res. 50(24): 14070-14083.

Cotton, T.M., Kim, J.H. \& Chumanov, G.D. 1991 . Application of surface-enhanced Raman spectroscopy to biological-systems. J. Raman Spectrosc. 22(12): 729-742.

Green, M. \& Liu, F.M. 2003. SERS substrates fabricated by island lithography: The silver/pyridine system. J. Phys. Chem. B 107(47): 13015-13021.

Hulchineon, K., Heater, R., Albery, J. \& Hillman, A.R. 1984. Raman Spectroscopic studies of a thionine modified electrode. J. Chem. Soc. Faraday Trans. 80: 2053-2071.

Kneipp, K., Wang, Y., Kneipp, H., Perelman, L.T., Itzkan, I., Dasari, R.R. \& Feld, M.S. 1997. Single molecule detection using surface-enhanced raman scattering. Phys. Rev. Lett. 78(9): 1667-1670.

Laurent, G., Fe'lidj, N., Aubard, J., Le'vi, G., Krenn, J.R., Hohenau, A., Schider, G., Leitner, A. \& Aussenegg, F.R. 2005. Evidence of multipolar excitations in surface enhanced Raman scattering. Phys. Rev. B. 71(4): 045430.

Li, B., Yu, D. \& Zhang, S. 1999. Raman Spectral study of silicon nanowires. Phys. Rev. B 59(3): 1645-1648.

Naujok, R.R., Duevel, R.V. \& Corn, R.M. 1993. Fluorescence and Fourier transform surface-enhanced Raman scattering measurements of methylene blue adsorbed onto a sulfurmodified gold electrode. Langmuir 9(7): 1771-1774.

Nie, S. \& Emory, S.R. 1997. Probing single molecules and single nanoparticles by surface-enhanced Raman scattering. Science 275(5303): 1102-1106.

Pavan, G.V., Kumar, S., Shruthi, B., Vibha, B.A., Ashok, R., Kundu, T.K. \& Narayana, C. 2007. Hot spots in Ag core$\mathrm{Au}$ shell nanoparticles potent for surface-enhanced Raman scattering studies of biomolecules.J.Phys. Chem.C. 111(11): 4388-4392.

Qianwang, C., Zhu, J., Lia, X.G., Fanab, C.G. \& Zhang, Y.H. 1996. Photoluminescence from porous silicon obtained by hydrothermal etching. Physics Letters A 220(4-5): 293-296.
Ruan, C., Luo, W., Wang, W. \& Gu, B. 2007. Single-molecule detection of thionine on aggregated gold nanoparticles by surface enhanced Raman scattering. J. Raman Spectrosc. 38(5): 568-573.

Tian, J.H., Liu, B., Li, X., Yang, Z.L., Ren, B., Wu, S.T. \& Tian, Z.Q. 2006. Study of molecular junctions with a combined surface-enhanced Raman and mechanically controllable break junction method. J. Am. Chem. Soc. 128(46): 1474814749.

Torchynska, T.V., Cano, A.D., Rodriguez, M.M. \& Khomenkova, L.Y. 2003. Hot carriers and excitation of $\mathrm{Si} / \mathrm{SiOx}$ interface defect photoluminescence in Si nanocrystallites. Physica $B$ 340: 1113-1118.

Xiao, G.N. \& Man, S.Q. 2007. Surface-enhanced Raman scattering of methylene blue adsorbed on cap-shaped silver nanoparticles. Chemical Physics Letters 447(4): 305-309.

Zhang, M.L., Fan, X., Zhou, H.W., Shao, M.W., Zapien, J.A., Wong, N.B. \& Lee, S.T. 2010. A high-efficiency surfaceenhanced Raman scattering substrate based on silicon nanowires array decorated with silver nanoparticles.J.Phys. Chem. C 114(5): 1969-1975.

Zhang, M.L., Peng, K.Q., Fan, X., Jie, J.S., Zhang, R.Q., Lee, S.T. \& Wong, N.B. 2008. Preparation of large-area uniform silicon nanowires arrays through metal-assisted chemical etching. Phys. Chem. C 112(12): 4444-4450.

Iram Mahmood*

Department of Industrial Engineering

College of Engineering

King Khalid University Abha 61413

Kingdom of Saudi Arabia

Ishaq Ahmad

National Center for Physics

Islamabad, 44000

Pakistan

Ishaq Ahmad

NPU-NCP Joint International Research Center

for Advanced Nanomaterials and Defects Engineering

Northwestern Polytechnical University

Xi'an 710072

China

Ishfaq Ahmad

Department of Mathematics and Statistics

Faculty of Basic and Applied Sciences

International Islamic University, Islamabad

Pakistan

*Corresponding author; email: irahmad@kku.edu.sa

Received: 11 February 2019

Accepted: 21 May 2019 